\title{
DISCURSO CON MOTIVO DE SU DESIGNACION COMO COLEGIAL MAYOR DE HONOR
}

\author{
Dr. Luis Reizabal S.J.
}

Creo poder asegurar que, en los ya veinticinco años que llevo en la Universidad, nunca he venido a este Paraninfo - y he tenido que hacerlo muchas - con la calma con la que vengo hoy.

Tres cosas me han atosigado siempre, y han sido y son mi tortura y mi tormento: levantarme pronto, o sea, madrugar; tener que afeitarme, y la tercera es: hablar en público.

Las tres me siguen acosando y persiguiendo: me levanto antes de la seis, aclarando que se trata de la mañana; no me decido a dejarme barba, y, en cuanto a hablar en público, si se puede llamar público a los 279 alumnos que cuatro veces por semana me esperan en el aula 5, veréis que difícilmente me libero de tales pesadumbres.

Y, sin embargo, he dicho que en esta ocasión vengo con una calma bien distinta de la pretendida otras veces.

Todo consiste en saberse el papel que a uno le toca y el mío se reduce, primero, a aceptar el homenaje que se me hace. Segundo, a justificar el título que lleva mi intervención en el acto. Tercero, a desarrollarla, como decía una empresa constructora, en el plazo convenido. Y no digo en el precio convenido porque no lo hemos puesto. Y por último, a medir mis palabras para «procurar» no pasarme del tiempo señalado.

En cuanto a designarme Colegial Mayor de Honor, confieso que todo lo colegial tiene para mí un atractivo íntimo que arranca desde el Mayor Menéndez Pelayo, que promoví en Valladolid y dirigí bastantes

Nota: La dirección de la revista Estudios de Deusto publica este discurso como homenaje al profesor emérito D. Luis Reizábal S.J., fallecido el 28 de diciembre de 1992. El texto transmite el sentimiento universitario y saber humanista tan característicos, que daba a sus intervenciones públicas. La conferencia fue pronunciada en noviembre de 1989 y es un buen ejemplo de su forma de vivir el ambiente deustense. 
años, y llega hasta el vuestro, en cuyos comienzos también me tocó hacer algo y lo hice.

Pero he de confesar también que, ante las distinciones honoríficas, pueden y suelen darse dos posturas. Una que, basándose en ciertos sentimientos de humildad, no acepta la designación alegando que no tiene méritos para ella.

La otra atiende más a la propia y personal comodonería.

Toda designación honorífica lleva consigo el pago de un tributo, en este caso la intervención personal que consta en el programa. Y ante situaciones parecidas a ésta, por no pagar el tributo, se puede decir: «me ofrecieron tal honor y no lo acepté». Aquí no se habla de falta de merecimientos pero subyace lo cómodo de evitar una labor, y un compromiso. En definitiva, aunque no siempre, lo que no se hace es lo que no compromete.

Pues bien, yo acepto lo que me han ofrecido como un cristiano y un hombre de mi condición religiosa debe aceptar un honor: con gratitud y con humildad.

Mi agradecimiento, pues, a la Corporación Colegial, con su Director y Junta Rectora. Unicamente siento que mis palabras de pago del tributo no tengan la calidad que merece la distinción que se me ha otorgado.

Y vamos con la segunda cuestión, que es justificar el título que he puesto a mi trabajo.

Trata de Estudios antiguos y encierra, por lo tanto, algo histórico, y tengo dos opiniones que van a ayudarme en su justificación.

La primera es de René Descartes, gran figura de influjo en el Renacimiento. Pues Descartes decía y escribió que «quien estudia con demasiada curiosidad lo que se hacía en tiempos pasados, termina por ignorar lo que se hace en el presente». Y es verdad. Hay tipos tan entregados a lo que encuentran en archivos y legajos, que su vida en el mundo corriente resulta desfasada.

La segunda opinión que me apoya, la expresa D. Francisco Tomás Valiente, que tal vez os sea más conocido como Presidente del Tribunal Constitucional que como catedrático de Historia del Derecho, que comenzó siéndolo en Salamanca.

En obra destinada a alumnos aventajados, escribe que «tan dañino como cultivar el estudio del pasado con poca atención a las cuestiones actuales, es el vivir un presente, cada vez más fugaz y efímero, con olvido de la Historia y dándole la espalda».

Y esto también es verdad.

Realmente ser histórico es una nota diferencial de lo humano. La historia es progreso, progresión, gradación, pero iniciada en la cuna del ayer. Arrancamos de atrás pero para ir adelante. 
Por eso en esta ocasión de fiesta y gaudeamus colegial, he querido traer al recuerdo algo de los tiempos pasados entreverando lo que había de fundamental en los Estudios y lo que tenían a veces, de pintoresco.

En el Código de las Partidas, se da una definición acabada de lo que eran los Estudios. «Estudio es el ayuntamiento de maestros et escolares que es fecho en algún lugar, con voluntad et con entendimiento de aprender los saberes». Es importante fijarse en que dice «con voluntad de aprender los saberes» y no de obtener un título o un grado.

Los Estudios Generales recibieron con el tiempo el nombre de Universidades.

Las tres primeras Universidades «de verdad» que hubo en España fueron las de Palencia, Salamanca y Valladolid, las tres con fundación pontificia que hacía que sus títulos valieran en toda la cristiandad.

La de Alcalá, que marcaría estilo nuevo frente a Salamanca, y sería junto con ella la más importante, la fundó el Cardenal Cisneros en 1508. La primera idea del Cardenal fue fundarla en su pueblo, Torrelaguna, que entonces, como ahora, cultivaba excelentes melones y sandías. Pero los del pueblo, que algo sabían de la vida de otras Universidades, le negaron todo apoyo, pensando que los estudiantes arrasarían sus huertas y se llevarían sus frutos. Cisneros, entonces, fundó su Universidad en Alcalá, en la que tuvo muchas alegrías académicas, y no volvió a pisar su pueblo. Bien es verdad que los años que le quedaban de vida los tuvo bien ocupados.

Pero, ¿qué era lo que a los vecinos de Torrelaguna les movía a rechazar a los estudiantes, a los que temían como a una peste anunciada?

Pues, seguramente, las noticias que tenían de las ciudades universitarias con varios siglos de vida.

A estas ciudades, a causa de sus Estudios, acudía gente de toda clase, naturaleza, estado y condición.

Acudían estudiantes caballeros, hijos de nobles, que montaban casa y llevaban criados para atenderles en los meses del curso; iban, también, religiosos de las Ordenes que buscaban formación académica para sus clérigos. Había Prelados que enviaban a los alumnos más selectos de sus diócesis y fundaban para ellos los Colegios Mayores. Y había también una afición enorme por el saber que concentraba en el lugar de los Estudios un número siempre grande y variado de escolares de características no siempre diferenciadas.

Y digo «no siempre diferenciadas», porque podía darse el caso de que un caballero estudiante, pudiera convertirse en un sopista o en un capigorrón, y que un capigorrista pudiera ser catedrático y hasta Primicerio de la Universidad. Explicaré pronto lo que eran estos tipos. 
Los Estudios estaban concebidos con seriedad y disciplina. En la Partida $6 .^{\mathrm{a}}$ se dice: «Otrosí pueden los escolares establecer de si mesmos un mayoral sobre todos, que en latín llaman Rector al que obedezcan en las cosas convenibles y derechas». (Difícil interpretación la del término Rector, cuando existían tantas otras Autoridades como Primicerio, Cancelario, Maestrescuela... No sabemos con certeza el papel de su cargo en cada época).

«Y el Rector debe apremiar a los estudiantes que non levanten bandos nin peleas entre sí mesmos, nin con los hombres de las villas donde estudian». Y añade más: «Debe defender que non anden de noche, más que están asosegados en su posadas y se empeñen en estudiar y hacer vida honesta y buena, (ca), pues los Estudios para eso fueron establecidos et non para andar de noche nin de día, peleándose o en otras maldades, a daño de sí et a estorgo de los lugres donde viven. Et si contra esto viniesen, el nuestro Juez los debe castigar y enderezar de manera que se quiten del mal et fagan el bien».

Este juez corresponde al establecimiento del Fuero Académico o universitario.

Lo concedió San Fernando a la Universidad de Salamanca y su hijo Alfonso X lo hizo extensivo a las demás.

Derivaciones del Fuero las hay en los innumerables privilegios, libertades y franquicias que se concedían a estudiantes y a más que estudiantes. Por eso se acogían al fuero académico personas totalmente ajenas al estudio, como taberneros, arrieros, pupileras, feriantes que se matriculaban, no para asistir a las aulas, sino para aprovecharse de los derechos y exenciones para meter vino o traer géneros, todo ello al amparo del Fuero Escolar con el creían tener patente de corso para sus andanzas por el mundo.

Los estatutos universitarios fueron rígidos en materia disciplinaria. No se permitía asistir con armas a las clases, pero se permitía al escolar tener en su aposento una espada de medida señalada.

Las patronas de las posadas debían dar, entre otras cosas, una libra de carne por la mañana y media por la noche, pero, pesándola con hueso, a veces no era mucho lo que se podía comer.

Había algo más. Tenían que cerrar las puertas con llave a las siete de la noche en invierno y a las diez el resto del año, para que los pupilos se recogieran con honestidad. No debían permitir jolgorios ni jaranas, todo ello bajo la pena de cerrarles la posada o no permitir que los escolares se hospedasen en ella.

Sin embargo, autores gloriosos de la picaresca han descrito el encanto y la alegría de una vida estudiantil alborotada, de poco estudio, 
viudas pupileras a quienes enamoriscar y sacar los cuartos, y jaranas nocturnas, porque los estudiantes tenían en sus habitaciones más armas y guitarras y vihuelas, que libros y apuntes.

Pasaba con seriedad y rigor la ronda universitaria de bedeles, alguaciles y corchetes visitando las casas, y todos, advertidos, estaban con sus cuadernos y cartapacios. Pero en cuanto marchaba, aparecía el mugriento y desencuadernado libro de las cuarenta hojas, los naipes, y a él le dedicaban gran parte de la noche. Me gustaría ver alguna baraja de los tiempos medievales, porque no existiendo en Vitoria la casa Fournier, tenían que ser, por su suciedad, de las que ya estaban prohibidas en el Ordenamiento de las Tafurerías que hizo el maestro Jacobo Roldán por encargo de Alfonso X.

Terminado el curso, los estudiantes pobres, igual que en toda Europa, regresaban en grupos a sus lugares cantando y pidiendo limosna o regalos, lo que dio origen a las «tunas» escolares. También en toda Europa se temía el paso por los pueblos de los estudiantes con el estilo recogido en los Carmina Burana.

Para algunos había habido cambio de situación. Caballeros o hijos de burgueses o terratenientes convertidos en sopistas. Si habían perdido todo en el juego y no les llegaba ayuda de sus casas, tenían que acogerse a la sopa de los conventos: un caldo con algo de berza, nabos y algún garbanzo para malvivir hasta los exámenes.

Algunos hijos de nobles podían volver esquilmados por los capigorrones. Covarrubias explica muy bien lo que esto significa: actividad practicable por estudiantes muy veteranos y con años de experiencia en no sacar los cursos aprobados, que se pegaban a estudiantes ricos o a pupileras tontas para comer a su costa.

En Andalucía se llamaba «gorrones» a los gusanos de seda que cuando los demás hilan sus capullos ellos no lo hacen, y engorran al desvarar la hebra de seda. Diego de Urrea dice que «gorrón» es nombre arábigo que significa engañar, y así a este gusano se «dixo» gorrón porque comió la hoja de morera y no contribuyó labrando como los demás.

Otra referencia a esta palabra la tenemos en la Universidad de Oviedo por los años 1608, cuando mermaron tanto sus rentas que los oficiales se refugiaban de gorrones en la Casa-hospital de estudiantes, pidiendo al claustro las ayudas precisas para vestir con decencia.

Pero en cambio los capigorristas, de origen más humilde, podían regresar con verdadera honra académica.

Antiguamente los criados de los estudiantes y de los Colegios Mayores traían capas y gorras. De aquí vinieron los nombres. Pero como algunos que también iban a Escuelas hacían los cursos con buenas notas, en las votaciones con cátedras ellos podían darlas o quitarles. Y 
cuenta Covarrubias que un opositor de su tiempo les captaba la benevolencia por un gracioso rodeo diciendo: «Los señores, mis señores, que sirven a otros señores, mereciendo ser servidos, y les soy su servidor».

Pues con ser así las cosas y tantas otras que se podrían citar con más tiempo, de esas Universidades salieron santos canonizados. (San Ignacio de Loyola supo lo que era caminar de pobre cuando dejó la Universidad de Salamanca para ir a la de París). Salieron prelados eminentes, religiosos eximios por su ciencia, oidores de Audiencias, magistrados de Chancillerías, miembros de los Consejos de Castilla o de Inmérito de los que no me es posible dar ni una muestra, y con pena me quedaría si no citase a un riojano humilde, Zenon de Somodevilla, capigorrista en el Colegio Mayor Santa Cruz de Valladolid, luego Marqués de la Ensenada, y autor de una Representación dirigida a Fernando VI sobre la reforma de los Estudios que es una maravilla.

Todos ellos participaron en disputas, y presenciaron ceremonias a las que voy a dedicar unas palabras.

Las disputas las podemos agrupar en tres clases: las que se hacían para opositar a las cátedras; las que se tenían en actos académicos para discutir sobre materias escolares, y las de tipo pendenciero que enfrentaban a los escolares entre sí, o a los estudiantes con los vecinos del lugar del Estudio.

No voy a entretenerme en las de oposiciones a las cátedras. Habría que exponer todo su complicado mecanismo y notar las enemistades y diferencias que se creaban si los de un Colegio Mayor o una Orden religiosa no votaban al aspirante de otra procedencia. La espléndida tesis del P. Juan Luis Cortina, catedrático de esta Universidad, contiene, con abundancia de datos y pulcritud de estilo, las situaciones acaecidas en los años que contempla sus tesis: los de la preilustración en España.

Las disputas académicas también creaban muchos problemas por las rivalidades que había entre los Maestros de la Universidad, los Colegios Mayores y las Ordenes religiosas adscritas al Estudio.

La adscripción se hacía mediante la matrícula, y en el Diario del Real Colegio de la Compañía en Salamanca se lee que el 15 de octubre de 1648 «vino el Oficial mayor del Secretariado de Escuelas a matricular a los superiores, maestros y estudiantes del Colegio. Diósele por dos un real de plata de a ocho, remitiéndole al P. Procurador».

En el archivo de manuscritos de la Universidad de Salamanca hay cuatro libros Diarios del Colegio de los jesuitas, que comprenden los años 1620 a 1707. Solamente voy a citar unas notas de muestra que indican el importante papel de los actos de disputas y el encono, a veces feroz, que había en las Escuelas. 
«1624. Noviembre 9. Hubo acto mayor e los Mínimos. Fueron allá nuestros maestros y algunos hermanos por haber enviado a pedir los PP. Mínimos que, atento a que se defendían nuestras opiniones (y por eso no iban a su acto los dominicos), no les dejasen solos por la tarde. (Se ve que era importante asegurarse de la asistencia cuando se sabía que, por las ideas que iban a exponerse, no acudirían los dominicos).

1625. Febrero 3. En el Colegio de los jesuitas.

Tuvo el acto mayor de Escuelas el P. Odriscol. Fue de materia de la Eucaristía. Presidiole el Mtro. Vitoria, del Orden de la Sma. Trinidad. Por la tarde hubo alguna revolución a causa de haber querido el dicho padre sustentante responder del todo a una autoridad de Sto. Tomás que puso en su argumento el mercedario, por lo cual los dominicos y mercedarios patearon de suerte que no dejaba pasar adelante el acto. Y así fue necesario que dos de los nuestros, fuesen a dar aviso de aquel desorden al Maestrescuela, el cual vino luego y les puso una descomunión si pateaban más y les trató bien ásperamente de palabra, con lo cual pasó adelante el acto con mucho silencio y paz y gran lucimiento del actuante. (Después de este acto es normal que el rector diera aloja y barquillos a todos los estudiantes).

1626. Diciembre 8. Hubo acto en san Bernardo. No fue nadie de casa porque ellos no vinieron al nuestro en noviembre sentidos de que en cátedra de prima favorecimos a fray Basilio. (Se ve otra vez que los resentimientos se guardaban).

1630. Diciembre 4. Fue el acto mayor de los dominicos. De praedestinatione. En las conclusiones decían las pesadumbres que suelen de nuestras opiniones. Arguyó el argumento de casa el P. Agustín Suárez, por la scientia media con eficacia y modestia, aunque el Presidente dijo perrerías de nuestra opinión. Se tuvo por locura. (Habría que ver ahora lo que sobre este caso se escribía en el convento de San Esteban de los dominicos salmantinos, donde la eficacia y modestia que narraba el jesuita, estarían valoradas de otra manera distinta).»

Pues así eran las disputas académicas con los enconos y rencillas manifestados sin el menor recato. León de Castro, furibundo antihebreísta, y Fray Luis de León, que quería traducir las Escrituras del hebreo, disputaron varios años seguidos, y Fray Luis dio en la cárcel por obra de la Inquisición.

Mayores y más graves, por atentar al orden y a la paz de la ciudad, eran las entabladas entre los propios estudiantes y entre éstos y los vecinos. Sólo citaré tres casos entre los casi infinitos que se pueden recoger de aquellos siglos históricos.

Una muy caracterizada fue la que sucedió en Alcalá en los primeros años de su existencia. La cuenta Alvar Gómez de Castro en De rebus gestis a Fco. Ximeno de Cisneros. El caso fue que llevaban a ahorcar a un platero por asesinato. Los estudiantes reaccionaron con violencia, 
apalearon a los ministros de la justicia y libertaron al reo llevándolo al convento de San Francisco donde le dieron asilo. El Derecho de asilo era cosa muy seria en aquel tiempo. Cisneros (tan autócrata) dijo que aquello era «la espuma del fervor académico» y que repetía «cosas de mis muchachos de Alcalá», y se susurró, por entonces, que no lo llevó a mal, porque el platero era un artesano hábil que trabajaba en la capilla de la Universidad en cosas de orfebrería.

Pero los vecinos no fueron de la opinión de Cisneros, y poco después, cansados de aguantar la indisciplina escolar, establecieron lo que se llama en términos poco cultos una «partida de la porra» para reprimir los desmanes, que salía por la noche a darse de estacazos con los estudiantes.

En Salamanca, en 1639, el vecindario armado asaltó la Universidad.

Resistieron los estudiantes entusiasmados. Los castellanos al grito de «viva la espiga». Al de «viva la aceituna», los andaluces. Los extremeños gritaban «viva el chorizo» y los navarros, «viva la bota de vino». Intervino un enviado de la Chancillería de Valladolid que llegó con tantos papeles para los procesos, que para aligerarle de su peso, quisieron quemárselos. La influencia del Corregidor y de Padres maestros de las Ordenes religiosas lograron atenuar la reyerta, aunque resultaron en ella gran número de heridos.

En noviembre de 1632 hubo una pendencia entre portugueses y vizcaínos, porque éstos trataron de judíos a los portugueses por haber herido a tres vizcaínos por deudas de juego. Se supo que se armaban para la noche, después de una mascarada, y no se pudo impedir. En los colegios se atendió a los heridos.

Pero con ser tan atrevidas las demasías de los estudiantes, lo curioso es que vibraban de fervor religioso, por ejemplo, cuando en 1618 la Universidad de Salamanca se adelantó a Roma en más de dos siglos, con un luminoso informe sobre la concepción inmaculada de María. Las fiestas y luminarias y poemas que se hicieron con ese motivo reflejan la impresionante variedad de actividades que cabían en el hacer universitario.

Se confesaban todas las Cuaresmas y oían pláticas doctrineras. Y el miércoles de ceniza, después de haberla recibido los estudiantes en sus cabezas, la ronda universitaria de corchetes, alguaciles y bedeles sacaba de la ciudad a las mujeres de vida no pudorosa que había en ella, y solían ser bastantes.

Pero pasada la Pascua, el día que llamaban «lunes de aguas» los estudiantes cruzaban el Tormes por el puente romano que también cruzó Lázaro con el ciego, y salían a esperarlas. Merendaban el hornazo que se hacía en las panaderías y montaban una romería que cambiando una 
sola letra podía convertirse en ramería. Después, en carros o a pie y con antorchas encendidas las entraban en la ciudad.

La vida normal de la Universidad se interrumpía muchas veces por la cantidad de fiestas y ceremonias que se celebraban.

Comienzo del curso, fiestas de Patronos de Facultad, visitas reales, o de delegados pontificios, bulas o pragmáticas en favor de los Estudios... todo era motivo para organizar mascaradas y algo que se saliera de lo corriente.

Lo más importante eran las ceremonias de colocación de Grados.

Un día de Grados era un día importante en la ciudad, pero era también un día en que muchas arcas quedaban esquilmadas por la cantidad de derechos y propinas que hacían que el acto, además de difícil, fuera costosísimo.

Difícil en lo académico. Los arguyentes eran siempre duros. Las conclusiones presentadas no eran fáciles y la dialéctica en la discusión inclinaba mucho la aceptación del Tribunal.

Por otra parte, el grado resultaba costosísimo en aquella Universidad. Lo dice Juan Ruiz de Alarcón, un mejicano que vino a graduarse y critica la carestía de los estudios.

La cosa empezaba de víspera. Tenían derechos propios en la «tentativa»o «repetición» el padrino, los examinadores y los bedeles. Pero además había que dar propinas largas a los que entapizaban la Universidad, a los que copiaban las conclusiones, cuando no había imprenta, a los atabaleros y trompeteros que servían de pregoneros del acto y naturalmente también al Maestro de ceremonias. Este cargo no era de excesiva importancia, pero como le hacían figurar en todas partes, de todas partes sacaba tajada.

Y llegado el día del Grado no tenían fin los derechos y propinas: a los campaneros de la Catedral porque hiciesen sonar bien las campanas; al Maestrescuela; al Secretario de la Universidad y al Sacristán de la capilla de N. Sra. de la Estrella donde oraba el aspirante.

No se podía olvidar a los encargados del recado de manteles y loza para la cena, a los camareros que la servían y a los músicos.

Había un tributo especial que siendo a voluntad nunca podía excusarse y era para «el arca de boda de la Universidad». Parece que la Universidad tenía, entonces, como las mozas de las serranías charras de Béjar, Peña de Francia y Gata, su arca de boda, cuyos fondos se incrementaban en estos actos y servían para atender las peticiones papales o reales que solían presentarse.

Los gastos crecían a maravilla con el refresco y la cena. Ruiz de Alarcón nos da detalles. Empezaba con un «ante», una especie de entremés de ensaladas. Seguía perdiz o pichón por cabeza. Libra y media 
de anguila o trucha, asimismo por barba. Jigote o perniles de tocino cocidos y fiambres. Aquí la palabra tocino significa el animal y no la capa que tiene entre sus costillas y la piel. Un «pos», postre de aceitunas, frutas, anises y barquillos. El indispensable «manjar blanco» que no voy a describir y dulces de los conventos de la ciudad.

El pan tenía que ser de leche. El agua, si fuere tiempo, de nieve, no faltando aloja, vino blanco y tinto a pedir de boca.

$\mathrm{Y}$ ya no me queda tiempo para hablar de las mascaradas, corridas de toros, vejámenes, y tantas cosas más.

Pues así eran las cosas en aquellos tiempos, contados sin orden en su cronología. Pero para terminar quiero deciros que entonces, como ahora, las carreras no estaban pensadas, ni lo están, para alumnos superdotados. Talentos normales y aun menos que normales triunfaban y triunfan en ellas con sólo poner en sus estudios tres ingredientes: ilusión, trabajo y constancia. Pero es importante que se den las tres. Con sólo alguno de ellos, el guisado académico personal no estaría bien sazonado.

Mirad la carrera como algo ilusionado que se proyecta a la sociedad y a vuestro futuro.

Trabajad en el estudio de los programas, con entrega y dedicación. Y sed constantes. No dejéis para el final, cuando llegan los exámenes, el querer hacer de prisa lo que, con paz y calma, pudisteis hacer antes.

En definitiva siempre será verdad lo que escribía Rudyard Kipling en un poema cuya lectura os recomiendo, incluso para tenerlo de «postor», y que termina así:

«Si llenas el minuto inolvidable y cierto de sesenta segundos que, en un trabajo pleno y lleno de alegría, te oriente hacia el cielo, todo lo de esta tierra será de tu dominio y lo que más importa, y mucho más aún, serás hombre, hijo mío».

Pues para formar hombres, se hicieron los Colegios Mayores. 